Research Article

\title{
Seasonal Prevalence of Japanese Encephalitis (JE) in Patna District of Bihar, India
}

\author{
Prashant Kumar', Ragini Mishra ${ }^{2}$, Roshan Kamal Topno ${ }^{3}$, Maneesh Kumar ${ }^{4}$, \\ Diwakar Singh Dinesh ${ }^{5}$, Dhrub Kumar Singh ${ }^{6}$ \\ ${ }^{1}$ District Health Society, Patna, Bihar, India. \\ ${ }^{2}$ State Health Society, Sheikhpura, Bihar, India. \\ 3,4,5ICMR-Rajendra Memorial Research Institute of Medical Sciences, Agamkuan, Patna, Bihar, India. \\ ${ }^{6} J a i$ Prakash University, Chhapra, Bihar, India. \\ DOI: https://doi.org/10.24321/0019.5138.201937
}

\section{I $\quad \mathbf{N} \quad \mathbf{F} \quad \mathbf{O}$}

\section{Corresponding Author:}

Diwakar Singh Dinesh, ICMR-Rajendra Memorial Research Institute of Medical Sciences, Agamkuan, Patna, Bihar, India.

E-mail Id:

drdsdinesh@gmail.com

Orcid Id:

https://orcid.org/0000-0002-1509-9133

How to cite this article:

Kumar P, Mishra R, Topno RK, Kumar M, Dinesh DS, Singh DK. Seasonal Prevalence of Japanese Encephalitis (JE) in Patna District of Bihar, India. J Commun Dis 2019; 51(4): 58-61.

Date of Submission: 2019-12-28

Date of Acceptance: 2020-01-07

\section{$\begin{array}{llllllll}\mathbf{A} & \mathbf{B} & \mathbf{S} & \mathbf{T} & \mathbf{R} & \mathbf{A} & \mathbf{C} & \mathbf{T}\end{array}$}

Background: Japanese Encephalitis (JE) is a major upcoming health problem in Bihar, India. JE is considered in the group of Acute Encephalitis Syndrome (AES) taking toll of pediatric age group every year in Bihar. The pattern of transmission of the disease in new areas based on seasonality is needed to be investigate.

Methods: Sources of data collection of AES and JE were Patna Medical College and Hospital, Patna and Nalanda Medical College and Hospital Patna through State health Society, Bihar, Patna. The vector and sera samples of pigs were collected from endemic zone. The central tendency statistical method was applied for analysis of data.

Result: In total 21 cases of AES were reported from two top-grade state hospitals at Patna like Patna Medical College Hospital and Nalanda Medical College Hospital in 2018. The cases were found prevalent throughout the year in 2018 between the temperature range of 5 으 to $49{ }^{\circ} \mathrm{C}$ and Relative humidity 11 to $100 \%$. The number of patients was high under the age of ten. The Japanese Encephalitis Virus (JEV) was also detected from the pigs. Eight sera samples of pigs out of 10 were found positive for JEV collected from the affected areas. The disease transmitting vectors like Culex tritaeniorhynchus and Culex vishnui were present in the locality. The case fatality was found $6.7 \%$ in the case of JE. All cases were treated in the hospitals.

Conclusion: The case fatality rate due to AES including JE was very high in Patna district. The cases of JE are appearing most of the months in the year. It is essential to scrutinize the cases in time and to implement the essential control measures to treat patient and to use insecticide to control vector to inhibit further transmission of the disease along with vaccination in due course of time.

Keywords: Japanese Encephalitis and Acute Encephalitis Syndrome, Mosquito, Pig 


\section{Introduction}

Japanese Encephalitis (JE) is a vector-borne communicable disease caused by Japanese Encephalitis Virus (JEV), a member of the genus Flavivirus (Family: Flaviviridae). The disease is transmitted between birds, pigs, and some other domestic animals by Culex mosquitoes. The first case of JE in India was reported from Vellore in $1955 .{ }^{1}$ In southern India, approximately 65 cases of JE were reported between 1955 and 1966.2 In between several outbreaks appeared in different states like Bihar, Madhya Pradesh, Uttar Pradesh, Assam, Manipur, Andhra Pradesh, Maharashtra, Tamil Nadu, Haryana, Kerala, West Bengal, Orissa, Goa, and Pondicherry. ${ }^{2,3}$ The annual incidence of the disease was found between 30,000 to 50,000 cases and the death between 10,000 to $15,000.4,5$ The disease can cause irreversible neurological damage. In Southern and Eastern Asia fatality rate was reported $30-50 \%$ and the survivors were found suffering from long term neurological manifestations in the form of convulsion, tremors, paralysis, and other symptoms in about $30-60 \%$ cases. ${ }^{6,7}$ In India, annual incidence ranged between 1765 and 3428 cases and deaths between 466 and 707, according to the National Vector Borne Disease Control Programme under the Ministry of Health and Family Welfare. In India, the epidemic was reported in 1978 including Bihar. ${ }^{9}$ The evidence appeared in Bihar by detecting neutralizing antibodies in birds from Asansol of Dhanbad regions. ${ }^{10}$ In the Gorakhpur district of Uttar Pradesh, 6061 cases and 1500 deaths occurred in 2006 and 3024 cases and 645 deaths occurred in 2007. ${ }^{11}$

\section{Materials and Methods}

The study was conducted with the data of 2018 for cases of JE and AES appeared in the villages and urban areas of Patna district admitted in the recognised Govt. hospitals at Patna like Patna Medical College and Hospital (PMCH) and Nalanda Medical College Hospital (NMCH). Patna district has 23 blocks stetted in 3, 202 square Kilometer at an elevation of 66-48 meters above the sea level and at longitude and altitude of $25.4840 \mathrm{~N}, 85.0233^{\circ} \mathrm{E}$. The data of admitted AES and JE cases during 2018 from Patna Medical College Hospital (PMCH) and Nalanda Medical College Hospital $(\mathrm{NMCH})$ were collected. The patient data were obtained from the State Health Society, Patna. The patients were diagnosed using the ELISA kit for confirmation of JE using the IgM antibody against JEV using the kit procured from ICMR-National Institute of Virology (NIV), Pune. The Patients diagnosed and treated in the hospital were included in the study. The patients admitted for fever history and negative for JE were excluded from this study. The vectors were collected from the affected areas using aspirator and flashlight from indoor resting houses and cattle sheds. Piggeries were found in the population. The blood samples of pigs were collected in June 2018 from affected villages of the Fatuha block. Samples were sent to 'Centre for Animal Disease Research \& Diagnosis, Indian Veterinary Research Institute, Izatnagar-243122 (Uttar Pradesh) for diagnosis of JEV. The ecological and environmental conditions in the locality were also assessed because of the transmission of JEV like the presence of water reservoirs and paddy plantations. The statistical analysis was conducted using the method of central diagnosis to analyse the basic data in analysing the data in mean, percent, etc.

\section{Result}

The JE cases were reported from Jan, March, April, May, July, October, November and December during 2018. The cases of AES appeared throughout the year except for April, May, September, October, and December (Table 1). The high number of JE cases i.e. 11 (73.3\%) out of 15 was reported in July, October, November and December. Overall the transmission of AES/ JE was found continuing throughout the year in Patna district except for September. Out of 23 blocks, cases were reported from 10 (43\%) blocks like Bakhtiyarpur, Patna, Punpun, Naubatpur, Fatuha, Paliganj, Punpun, Danapur, Masurhi, and Bihta. In total 6 AES (28.6\%) and $15 \mathrm{JE}$ (71.4\%) cases were admitted in both $\mathrm{PMCH}$ and $\mathrm{NMCH}$ hospital of Patna district during 2018. Amit Kumar at the age of one and half years of Machhariyama village of Fatuha block was diagnosed and treated for JE at NMCH Patna in April 2018. JE vectors like Culex tritaeniorhynchus, C. pseudovishnui, and C. gelidus with the Man Hour Density (MHD) of 3:1:1 respectively. In Machhariyama village; Mansonia annulifera (1MHD) adult was collected. Larvas ( $M$. annulifera) were collected from ponds having Pistia (Pistia stratiotes) plants (density was 1 per dip). Pig population was approximately 1000 in the village distributed in three tolas of Musahar Community having the lowest socio-economic status depends on daily wages. About 25 pigs died due to some problems like a continuous discharge of saliva, slugginess, and closing of eyes till two days. No paddy farm was in the locality. The water reservoir was found having grasses on the bank. The pig serum samples collected from these localities were found positive for JEV in 8 out of 10.

The patients were clinically diagnosed as Acute Encephalitis Syndrome(AES), having high grade fever $(>39 \circ C)$ with any two of the following symptoms like headache, vomiting, unconsciousness, convulsions, abnormally movements, stupor, delirium, altered sensorium, neck rigidity, presence of Kernig's signs admitted to the well equipped two medical colleges, $\mathrm{PMCH}$ and $\mathrm{NMCH}$ situated in Patna district; the study area. The cases of JE were scrutinized through the test. In Patna district cases of AES were found appearing throughout the year except for September in 2018. In total 21 cases of AES were admitted in both Medical colleges during 2018, of which 6 (28.6\%) were AES and rest were JE. 
Table I.Seasonal prevalence of AES and JE in Patna district and correlation with meteorological data

\begin{tabular}{|c|c|c|c|c|}
\hline Month & AES & JE & Av Temp & Av RH \\
\hline January & 1 & 1 & 13 & 87 \\
\hline February & 1 & 0 & 21 & 68 \\
\hline March & 1 & 1 & 26 & 52 \\
\hline April & 0 & 1 & 30 & 53 \\
\hline May & 0 & 1 & 31 & 65 \\
\hline June & 1 & 0 & 33 & 64 \\
\hline July & 1 & 2 & 33 & 64 \\
\hline August & 1 & 0 & 30 & 83 \\
\hline September & 0 & 0 & 30 & 81 \\
\hline October & 0 & 3 & 27 & 73 \\
\hline November & 0 & 3 & 22 & 68 \\
\hline December & 0 & 3 & 16 & 67 \\
\hline Total & 6 & 15 & & \\
\hline
\end{tabular}

\section{Discussion}

In Bihar, the JE incidence was found from May to December. AES was found in epidemic form in Muzaffarpur district of Bihar starting from May- June and last up to July. ${ }^{12}$ The fatality rate in the study was found $50 \%$ due to AES and $6.7 \%$ due to JE. However, it was 31\% with AES in Muzaffarpur district. ${ }^{13}$ The first case of the Chandipura virus affected patient was scrutinized under AES in Gaya. ${ }^{14}$ The age group of AES patients was found 1-15 years. It was 1-18 years in the case of JE. The age group of 1-10 was found highly affected i.e. $73 \%$ with JE with $40 \%$ male and $33 \%$ females. The male and females in the age group of 1-10 was also found highest with $46 \%$ male and $31 \%$ females in West Bengal. ${ }^{15}$ Out of 15 cases of JE, the serum of pigs were collected from one affected village Machhariyama, Bankipur and Daniyma at Fatuha PHC and tested for antibody against JEV and fund 8 samples positive out of 10 . Serum samples of 404 pigs from eight affected districts of Bihar tested for haemagglutination inhibiting and complement-fixing antibodies of JE, Dengue-2, West Nile and Chikungunya viruses. JE was found widely prevalent in comparison to others. High geometric mean titer to JEV was observed and the vector of JE was found in the locality. ${ }^{16}$

JEV has been isolated from more than 15 species of mosquitoes in India belonging to the genera Culex, Aedes and Anopheles. C. tritaeniorhynchus and C. vishnui are considered as the main sectors. About 6000 cases and 1500 deaths occurred during 2005 in eastern Uttar Pradesh. JE vaccine in endemic areas was introduced after that. Bihar as an adjacent state to eastern Star Pradesh has also reported a rise in the number of patients of AES and JE with periodic
Epidemics in some districts, including Muzaffarpur district. ${ }^{17}$ After the outbreak of JE in Gorakhpur and Basti divisions in the eastern Uttar Pradesh during 2005, the National Vector Borne Disease Control Programme (NVBDCP) made a surveillance guideline. ${ }^{18}$

The trend of occurrence of AES and JE in Patna district of Bihar is different from other places in the view of seasonality, meteorological data, presence of vector and infected pig as reservoir causing transmission of JE throughout the year. The study needs to be explored in detail to check the transmission of the diseases.

\section{Conclusion}

The case fatality rate due to AES including JE was very high in Patna district. The cases of JE are appearing most of the months in the year. The reservoir host and transmitting mosquitoes vectors were present in the locality. It is essential to scrutinize the cases in time and to implement the essential control measures to treat patient and to use insecticide to control vector to inhibit further transmission of the disease along with vaccination in due course of time.

\section{Acknowledgement}

The authors are thankful to the technical staffs at RMRIMS, Patna for evaluation of vector density, Centre for Animal Disease Research and Diagnosis, Indian Veterinary Research Institute, Izatnagar for detection of JEV antibody in pig serum.

\section{Conflict of Interest: None \\ References}

1. Namachivayam V, Umayal K. Profile of the 1981 epidemic of encephalitis in South Arcot district. In: Proceedings of the National conference on Japanese Encephalitis. Indian J Med Res 1982; 47: 30-33. [Google Scholar].

2. Carey DE, Myers RM, Pavri KM. Japanese encephalitis studies in Vellore, South India. Part II. Antibody response of patients. Indian J Med Res 1968; 56(9): 1319-1329. Available from: https://www.cabdirect.org/cabdirect/ abstract/19692704295 [PubMed/ Google Scholar].

3. Potula R, Badrinath S, Srinivasan S. Japanese encephalitis in and around Pondicherry, South India: a clinical appraisal and prognostic indicators for the outcome. J Trop Pedia 2003; 49(1): 48-53. Available from: https:// academic.oup.com/tropej/article/49/1/48/1734702 [PubMed/ Google Scholar].

4. Kabilan L, Vrati S, Ramesh S, Vrati S. Japanese encephalitis virus (JEV) is an important cause of encephalitis among children in Cuddalore district, Tamil Nadu, India. J Clinic Virol 2004; 31(2): 153-159. [Google Scholar/ ResearchGate].

5. Erlanger TE, Weiss S, Keiser J, Utzinger J, Wiedenmayer 
K. Past, present, and future of Japanese encephalitis. Emerg Infect Dis 2009; 15(1): 1-7. Available from: https://pubmed.ncbi.nlm.nih.gov/19116041-pastpresent-and-future-of-japanese-encephalitis/ [Google Scholar].

6. Solomon T. Control of Japanese encephalitis-within our grasp? New Eng J Med 2006; 355(9): 869-871. Available from: https://www.nejm.org/doi/full/10.1056/ NEJMp058263 [Google Scholar].

7. Kabilan L, Rajendran R, Arunachalam N, Ramesh S, Srinivasan $S$ et al. Japanese encephalitis in India: an overview. Indian J Pedia 2004; 71(7): 609-615. Available from: https://link.springer.com/article/10.1007/ BF02724120 [PubMed/ Google Scholar].

8. Tsai TF, Chang G, Yu Y. Japanese encephalitis vaccines. Vaccines Plotkin SA, Orenstein WA. 1999, WB Saunders Co, Philadelphia. [Google Scholar].

9. NVBDC P. Directorate General of Health services Ministry of Health and Family Welfare, New Delhi. Cited April 4, 2009. Available from: http://nvbdcp. gov.in/je-cd.html.

10. Khan F, Banerjee K. Mosquito collection in heronries and antibodies to Japanese encephalitis virus in birds in Asansol-Dhanbad region. Indian J Med Res 1980; 71: 1-5. [PubMed/ Google Scholar].

11. Kabilan L. Control of Japanese encephalitis in India: a reality. Indian J Pedia 2004; 71(8): 707-712. Available from: https://link.springer.com/article/10.1007/ BF02730659 [Google Scholar].

12. Kumar P, Pisudde PM, Sarthi PP, Sharma MP, Keshri VR. Status and trend of acute encephalitis syndrome and Japanese encephalitis in Bihar, India. Nat Med J India 2017; 30(6): 317-320. Available from: http:// www.nmji.in/article.asp?issn=0970-258X;year $=2017$ ; volume $=30$; issue $=6$; page $=317$; epage $=320$; aulast $=\mathrm{K}$ umar [Google Scholar].

13. Dinesh DS, Pandey K, Das VNR et al. Possible factors causing acute encephalitis syndrome outbreak in Bihar, India. Int J Curr Microbiol App Sci. 2013; 2(12): 531538. Available from: https://pdfs.semanticscholar. org/00ee/3d483cb8a8ab16697cbd535d9e3b1fcf6bba. pdf [Google Scholar].

14. Dinesh DS, Topno RK, Pandey K, et al. Chandipura virus recognized among AES for the first time in Bihar, India. Int J Curr Microbial App Sci 2018; 7(12): 36583663. Available from: https://pdfs.semanticscholar. org/0da8/d2bf9d7ab7aae1ec44b3ad7a518a9ffe8b60. pdf [Google Scholar].

15. Sarkar A, Taraphdar D, Mukhopadhyay BB, Kumar M, Mukhopadhyay SK, Chatterjee S. Influence of socio-economic status and environmental factors on serologically diagnosed Japanese encephalitis cases in the state of West Bengal, India during 2005-2010. Health
2012; 4(1): 6-12. Available from: https://www.scirp. org/journal/PaperInformation.aspx?PaperID=16985 [Google Scholar].

16. Kalimuddin MD, Narayan KG, Choudhary SP. Serological evidence of Japanese encephalitis virus activity in Bihar. Inter J Zoon 1982; 9(1) 39-44. [PubMed/ Google Scholar].

17. Mishra R, Kumar G. Epidemiological report on Acute Encephalitis Syndrome (AES)/Japanese Encephalitis (JE) outbreak in Bihar \& planning perspectives for its control. Am J Health Res 2014; 2(6): 404-410. Available from: http://www.sciencepublishinggroup.com/ journal/paperinfo?journalid=656\&doi=10.11648/j. ajhr.20140206.24 [Google Scholar].

18. Guidelines: Clinical management of acute encephalitis syndrome including Japanese encephalitis. National Vector Borne Disease Control Programme, Directorate General of Health Services, Ministry of Health and Family Welfare, New Delhi. 2009. 